Article

\title{
Investigation on the Deposition of an AlN-ZnO/ZnO/AlN-ZnO Double Heterojunction Structure Using Radio Frequency Magnetron Cosputtering Technology
}

\author{
Yu-Kai Zheng ${ }^{1}$, Yang-Zheng Zhang ${ }^{1}$, Hsin-Ying Lee ${ }^{2}$, Ching-Ting Lee ${ }^{3}$, Ruei-Hao Huang ${ }^{1}$ and \\ Day-Shan Liu ${ }^{1, *}$ \\ 1 Institute of Electro-Optical and Material Science, National Formosa University, 63201 Yunlin, Taiwan \\ 2 Department of Photonics, National Cheng Kung University, 70101 Tainan, Taiwan \\ 3 Department of Photonics Engineering, Yuan Ze University, 32002 Taoyuan, Taiwan \\ * Correspondence: dsliu@sunws.nfu.edu.tw; Tel.: +886-5-6315665
}

Received: 15 July 2019; Accepted: 21 August 2019; Published: 25 August 2019

\begin{abstract}
A symmetric AlN-ZnO/ZnO/AlN-ZnO double heterojunction structure was consecutively deposited onto silicon substrate using cosputtering technology and then annealed at $700{ }^{\circ} \mathrm{C}$ under vacuum ambient for $30 \mathrm{~min}$. The crystalline quality of the $\mathrm{ZnO}$ film in the heterojunction structure was significantly improved as verified by X-ray diffraction (XRD) and photoluminescence (PL) measurements. Improvement on the crystalline structure was ascribed to the stress in the $\mathrm{ZnO}$ active film, which was effectively buffered by the underlayered AlN-ZnO layer. Native oxygen vacancies in the $\mathrm{ZnO}$ film also were effectively suppressed due to a little diffusion of the $\mathrm{Al}$ atoms from the cosputtered AlN-ZnO layer, and led to an increase in the carrier concentration. Such $\mathrm{ZnO}$ film deposited onto the homogeneous AlN-ZnO buffer layer emitted an intense near-band-edge emission, and the deep level emission was absent. The ultraviolet emission was further enhanced by covering an $\mathrm{AlN}-\mathrm{ZnO}$ barrier laye, which was a consequence of the improvement on the carrier confinement. Accordingly, single ultraviolet emission with a quality $\mathrm{ZnO}$ crystalline structure, which is very promising for application in short-wavelength optoelectronic devices, was realized from the $\mathrm{ZnO}$ film sandwiched by the homogeneity of the cosputtered AlN-ZnO layers.
\end{abstract}

Keywords: symmetric double heterojunction structure; cosputtering technology; $\mathrm{ZnO}$; cosputtered AlN-ZnO; homogeneous buffer layer; carrier confinement

\section{Introduction}

Zinc oxide $(\mathrm{ZnO})$ is a direct group II-VI binary compound semiconductor with a wide energy bandgap of $3.37 \mathrm{eV}$, which is similar to that of gallium nitride $(\mathrm{GaN})$. It has a larger exciton binding energy of $60 \mathrm{meV}$ at room temperature, allowing efficient and stable excitonic emission against thermal dissociation for ultraviolet (UV) light-emitting diode (LED) and laser diode application. Compared to the complicated and hazardous dry etching process for patterning GaN material in device fabrication, patterned $\mathrm{ZnO}$ is achievable by the common wet etching process, since it is very sensitive to most acids, such as hydrochloric acid. Accordingly, $\mathrm{ZnO}$ material is expected to be more promising than the current mainstream GaN-based device for short-wavelength optoelectronic applications [1-4]. Additionally, the growth in technology and temperature necessary to realize a $\mathrm{ZnO}$ film with quality $c$-axis crystallization is much simpler, such as when done by sputtering, pulse laser deposition, and hydrothermal methods, rather than for the epitaxial GaN layer, resulting in potentially low-cost fabrications and processes for ZnO-based devices [5-8]. Among these deposition methods, 
sputtering technology is a commercially used method for preparing large-area and cost-efficient polycrystalline $\mathrm{ZnO}$ layers on various substrates in applications for optoelectronic devices at a relatively low temperature. However, the ion-bombardment damage from the sputtering deposition always caused the resulting $\mathrm{ZnO}$ film to diverge from stoichiometry, which was mainly attributed to a deficiency in oxygen atoms. Moreover, the quality of the $\mathrm{ZnO}$ film was closely connected with the substrate materials. Accordingly, intermediate layers such as $\mathrm{TiO}_{2}, \mathrm{Al}_{2} \mathrm{O}_{3}, \mathrm{Cr}_{2} \mathrm{O}_{3}, \mathrm{Lu}_{2} \mathrm{O}_{3}, \mathrm{AlN}$, and $\mathrm{Ti}$-which were prepared prior to $\mathrm{ZnO}$ film deposition to facilitate the crystalline growth as well as an additive post-annealing treatment on the $\mathrm{ZnO}$ film for re-crystallization-were reported to improve the sputtered $\mathrm{ZnO}$ film with fewer native defects [9-16]. For instance, Zhang et al. reported a SiC buffer layer to reduce defect density in the $\mathrm{ZnO}$ film induced by the Si substrate. Xu et al. used a heterogeneous buffer layer of $\mathrm{TiO}_{2}$ thin film to improve the preferential orientation along the $c$-axis growth and to enhance the UV emission of the $\mathrm{ZnO}$ thin film due to the buffer layer preventing $\mathrm{Si}$ atoms from capturing oxygen atoms in the $\mathrm{ZnO}$ film. In addition, Zhang et al. employed a metallic Ti layer to improve the crystallinity of the sputtered $\mathrm{ZnO}$ film as deposited onto the Si and glass substrates. More recently, Wang et al. used an AlN buffer layer to solve the large lattice mismatch and thermal expansion coefficient between the $\mathrm{ZnO}$ layer and $\mathrm{Si}$ substrate to improve the $c$-axis growth orientation and to realize a quality $n-\mathrm{ZnO} / \mathrm{AlN} / p$-Si heterojunction diode. In addition to realizing a quality $\mathrm{ZnO}$ film with better $c$-axis preferential growth via depositing it onto a specific buffer layer, most semiconductor devices rely on double heterostructures (DH) to provide efficient carrier and/or optical confinement. Barrier layers with conduction-band and valence-band offsets between the individual layers have been designed to sandwich the $\mathrm{ZnO}$ film for effective confinement of the generated and/or injected carrier in this active layer, which achieves a quality ZnO-based optoelectronic application. Currently, the development of $\mathrm{MgZnO}$ and $\mathrm{CdZnO}$ alloys had been reported to realize bandgap engineering in $\mathrm{ZnO}$ films over a wide range [17-22]. Kong et al. fabricated a $\mathrm{MgZnO} / \mathrm{ZnO}$ double heterojunction diode using a molecular beam epitaxy system to achieve good rectification behavior with the strong dominant UV emission. Ohashi et al. grew a high-quality $\mathrm{MgZnO} / \mathrm{CdZnO} / \mathrm{MgZnO}$ double heterojunction structure by a remote plasma-enhanced metal-organic chemical vapor deposition to improve red electroluminescence (EL) emission. Li et al. and Pandey et al. respectively fabricated $\mathrm{Sb}$-doped $\mathrm{ZnO} / \mathrm{CdZnO} / \mathrm{Ga}$-doped double heterojunction structures by plasma-assisted molecular beam epitaxy and a dual ion beam sputtering deposition system. They both showed that a $p-i-n \mathrm{ZnO}$-based diode yielded blue electroluminescence at around $446 \mathrm{~nm}$ as a result of the effective confinement of the injected electron-hole pairs in the $\mathrm{CdZnO}$ active layer. Li et al. also fabricated the $\mathrm{MgZnO} / \mathrm{ZnO} / \mathrm{GaN}$ and $\mathrm{MgZnO} / \mathrm{ZnO} / \mathrm{Si}$ asymmetric $p$ - $i-n$ double heterojunction LED structures using molecular beam epitaxy, and discussed their EL spectra at violet-ultraviolet wavelengths on different lattice-mismatched substrates. Moreover, Shi et al. realized electrically driven ultraviolet random lasing from a $\mathrm{MgZnO} / \mathrm{ZnO} / \mathrm{SiO}_{2}$ asymmetric double heterostructure as a result of the hollow-shaped $\mathrm{SiO}_{2}$ cladding layer to prevent a path for current leakage and achieve a waveguide mechanism.

Motivated by the above-mentioned ideas, a homogeneous or heterogeneous buffer layer was deposited between the $\mathrm{ZnO}$ film and substrate to suppress the formation of native defects in the $\mathrm{ZnO}$ film as a result of the release of the residual internal stress. Moreover, symmetric or asymmetric barrier layers with bandgap engineering to sandwich the $\mathrm{ZnO}$ film was essential for providing better carrier and optical confinement in the active $\mathrm{ZnO}$ layer for optoelectronic device applications. In the previous work, we demonstrated that the conduction type, optical energy bandgap, and crystalline structure of a cosputtered AIN (aluminum nitride)-ZnO film were controllable by simply altering the theoretical atomic ratios of the $\mathrm{Al}$ in the cosputtered film $[23,24]$. In this work, this cosputtered AlN-ZnO film was employed as a homogeneous buffer layer, while the $\mathrm{ZnO}$ film was deposited onto the silicon substrate. Furthermore, a symmetric double heterojunction structure constructed from the $\mathrm{ZnO}$ film sandwiched in between the cosputtered AlN-ZnO layers was consecutively deposited onto the silicon substrate using this cosputtering technology. The improvement in the crystalline structure of the 
$\mathrm{ZnO}$ film while deposited onto the homogeneous AlN-ZnO film was studied. The achievement in carrier confinement was evidence of the enhancement on the ultraviolet radiative emission from the symmetric $\mathrm{AlN}-\mathrm{ZnO} / \mathrm{ZnO} / \mathrm{AlN}-\mathrm{ZnO}$ double heterojunction structure.

\section{Material Preparation and Experimental Procedure}

An undoped $\mathrm{ZnO}$ film and the cosputtered AlN-ZnO films at the theoretical atomic ratios of $20 \%$ and $40 \%(\mathrm{Al} /(\mathrm{Al}+\mathrm{Zn})$ at. $\%)$, respectively, with thicknesses of 300 and $100 \mathrm{~nm}$ were individually deposited onto silicon and sapphire substrates by a radio frequency (RF) magnetron cosputtering system, and then annealed at $700{ }^{\circ} \mathrm{C}$ under a vacuum ambient for $30 \mathrm{~min}$. Targets of $\mathrm{ZnO}$ and AlN were employed as the source material for preparing these cosputtered AlN-ZnO films at room temperature under the working pressure of $1.33 \mathrm{~Pa}$ and argon ambient of $15 \mathrm{sccm}$. The RF power supplied on the AlN target was fixed at $85 \mathrm{~W}$, while the RF power on the $\mathrm{ZnO}$ target was controlled at 70 and $155 \mathrm{~W}$, respectively, to obtain the cosputtered AlN-ZnO films at the atomic ratios of $20 \%$ and $40 \%$. Technology to derive the theoretical atomic ratio of the $\mathrm{Al}$ concentration in the cosputtered AlN-ZnO film using the deposition rates have been reported elsewhere [23]. After determining the electrical, optical, and material properties of these annealed undoped $\mathrm{ZnO}$ and cosputtered AlN-ZnO films, the crystallinity and radiative properties of a 100-nm thick undoped $\mathrm{ZnO}$ film consecutively deposited onto the cosputtered AlN-ZnO film at a thickness of $50 \mathrm{~nm}$ using the RF magnetron cosputtering system were investigated, as well as the annealed treatment afterwards. The material and optical properties of the undoped $\mathrm{ZnO}$ film sandwiched in between the cosputtered AlN-ZnO films (the $\mathrm{AlN}-\mathrm{ZnO} / \mathrm{ZnO} / \mathrm{AlN}-\mathrm{ZnO}$ double heterojunction structure is depicted in Figure 1) that was deposited consecutively by the RF magnetron cosputtering system and then annealed at $700{ }^{\circ} \mathrm{C}$ under vacuum ambient for $30 \mathrm{~min}$ was also studied.

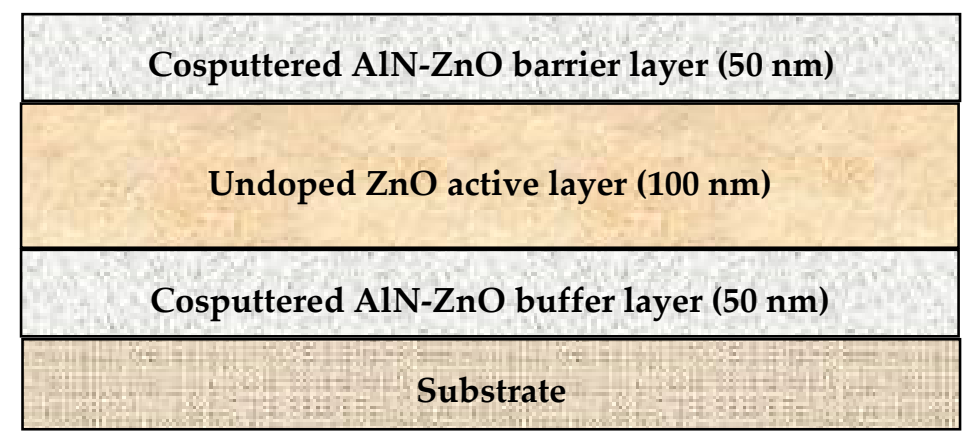

Figure 1. A schematic structure of the $\mathrm{AlN}-\mathrm{ZnO} / \mathrm{ZnO} / \mathrm{AlN}-\mathrm{ZnO}$ double heterojunction structure.

Film thickness was measured using a surface profile system (Dektak 6M, Veeco, Plainview, NY, USA). The electrical properties of the undoped $\mathrm{ZnO}$ and cosputtered AlN-ZnO films as well as the $\mathrm{AlN}-\mathrm{ZnO} / \mathrm{ZnO}$ heterojunction and $\mathrm{AlN}-\mathrm{ZnO} / \mathrm{ZnO} / \mathrm{AlN}-\mathrm{ZnO}$ double heterojunction structures were investigated using the van der Pauw Hall measurements (Ecopia HMS-5000, Ecopia, Anyang, South Korea) at room temperature. The optical transmittance of the undoped $\mathrm{ZnO}$ and cosputtered AlN-ZnO films were examined by an UV-Vis-NIR spectrophotometer (UVD 3500, Labomed, Inc., Los Angeles, CA, USA). Surface morphologies of the undoped $\mathrm{ZnO}$ and cosputtered AlN-ZnO films were observed using a field emission scanning electron microscope (FE-SEM, JSM-6700F, JEOL, Akishima, Japan). Radiative characteristics of the single undoped $\mathrm{ZnO}$ and cosputtered AlN-ZnO films as well as the heterojunction and double heterojunction structures were investigated from their photoluminescence (PL) spectra measured at room temperature using a home-setup He-Cd laser $(\lambda=325 \mathrm{~nm})$ as the pumping source. The crystallinity of these samples was determined from X-ray diffraction (XRD) patterns using a diffractometer (Siemens D-500, Siemens, Munich, Germany) with a $\mathrm{Cu} \mathrm{K} \alpha$ radiation source. Elemental distributions of the $\mathrm{AlN}-\mathrm{ZnO} / \mathrm{ZnO} / \mathrm{AlN}-\mathrm{ZnO}$ double heterojunction structures were examined by Auger electron spectroscopy (AES) depth profiles on a scanning Auger 
nanoprobe (PHI 700, Ulvac-PHI, Kanagawa, Japan). In addition, the $\mathrm{Al}$ content in these AlN-ZnO films at the theoretical values of $20 \%$ and $40 \%$ also had been measured by the energy-dispersive $X$-ray spectroscope (EDS) quantitative analysis EDS equipment attached to the FE-SEM system $(\sim 9.5 \%$ and $45.0 \%)$ and the AES ( $22.1 \%$ and $46.7 \%)$, respectively.

\section{Results and Discussions}

Figure 2a shows the optical transmittance of the 300-nm thick undoped $\mathrm{ZnO}$ film and cosputtered $\mathrm{AlN}-\mathrm{ZnO}$ films at theoretical $\mathrm{Al}$ atomic ratios of $20 \%$ and $40 \%$, respectively, annealed at $700{ }^{\circ} \mathrm{C}$ for 30 min under vacuum ambient. All these annealed films exhibited a high optical transmittance at visible wavelengths. The average transmittance at visible wavelengths (400 to $700 \mathrm{~nm})$ of the cosputtered AlN-ZnO (40\%) film ( $94.5 \%)$ was a little higher than that of the undoped $\mathrm{ZnO}$ and AlN-ZnO $(20 \%)$ films (of about $89.0 \%$ and $89.8 \%$, respectively).

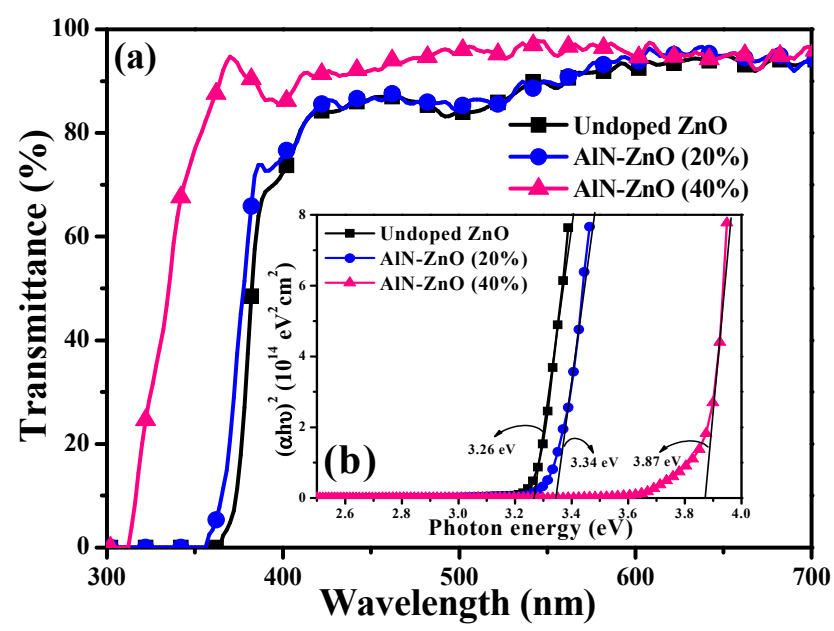

Figure 2. (a) Optical transmittance of the undoped $\mathrm{ZnO}$ film and the cosputtered AlN-ZnO films at a theoretical $\mathrm{Al}$ atomic ratio of $20 \%$ and $40 \%$, respectively, annealed at $700{ }^{\circ} \mathrm{C}$ for $30 \mathrm{~min}$ under vacuum ambient ((b) corresponding optical energy bandgap evaluated from the relationship between $(\alpha \mathrm{h} v)^{2}$ and photon energy $\left.\left(E_{\mathrm{g}}\right)\right)$.

For the cosputtered AlN-ZnO film at an $\mathrm{Al}$ theoretical atomic ratio of $20 \%$, the absorption edge that occurred at the sharp reduction in optical transmittance was found to shift toward a shorter wavelength as compared to the undoped $\mathrm{ZnO}$ film, and an apparently blue shift on the absorption edge was observed from the cosputtered $\mathrm{AlN}-\mathrm{ZnO}$ film as the $\mathrm{Al}$ atomic ratio reached $40 \%$. The corresponding optical energy bandgap evaluated from the relationship between $(\alpha \mathrm{h} v)^{2}$ and photon energy $\left(E_{\mathrm{g}}\right)$ [25], as shown in the inset figure of Figure $2 b$, was markedly widened from 3.26 to $3.87 \mathrm{eV}$ as the AlN was introduced into the $\mathrm{ZnO}$ film at a theoretical $\mathrm{Al}$ atomic ratio of $40 \%$. As referred to the reports on the energy bandgap of $\mathrm{MgZnO}$ and $\mathrm{CdZnO}$ alloys modified by the bandgap of $\mathrm{MgO}\left(E_{\mathrm{g}} \approx 7.7 \mathrm{eV}\right)$ and $\mathrm{CdO}$ $(\sim 2.3 \mathrm{eV})[18,19,21,22]$, the large energy bandgap of the AlN $(\sim 6.3 \mathrm{eV})$ was likely responsible for the widening optical energy bandgap of the cosputtered $\mathrm{AlN}-\mathrm{ZnO}$ films, resulting in the high transmittance at the UV wavelengths. Moreover, the higher transmittance of the cosputtered AlN-ZnO at an atomic ratio of $40 \%$ around the visible wavelengths was attributed to the lower refractive index of AlN than $\mathrm{ZnO}$. Table 1 summarizes the electrical properties of the as-deposited and annealed undoped $\mathrm{ZnO}$ films as well as the cosputtered $\mathrm{AlN}-\mathrm{ZnO}$ films at a theoretical $\mathrm{Al}$ atomic ratio of $20 \%$ and $40 \%$ with the thickness of $100 \mathrm{~nm}$, respectively, determined from Hall effect measurements at room temperature. The as-deposited undoped $\mathrm{ZnO}$ film showed an insulated nature with a resistivity, $\rho$, higher than the instrument limit ( $>10^{5} \Omega \cdot \mathrm{cm}$ ), while the as-deposited AlN-ZnO $(20 \%)$ film behaved as an $n$-type conduction with the electron carrier concentration, $n$, of approximately $6.5 \times 10^{18} \mathrm{~cm}^{-3}$. The $n$-type conduction of the as-deposited AlN-ZnO (20\%) was ascribed to the activation of the $\mathrm{Al}^{3+}$ ions as donor 
substitutions for the $\mathrm{Zn}^{2+}$ lattice sites (i.e., $\mathrm{Al}_{\mathrm{Zn}}$ ) [23]. However, for the $\mathrm{ZnO}$ film cosputtering with the $\mathrm{AlN}$ at an $\mathrm{Al}$ atomic ratio of $40 \%$, the resistivity of the as-deposited $\mathrm{AlN}-\mathrm{ZnO}(40 \%)$ film became too high to be measured. The undoped $\mathrm{ZnO}$ film annealed at $700{ }^{\circ} \mathrm{C}$ for $30 \mathrm{~min}$ under vacuum ambient resulted in $n$-type degenerated conduction, while the cosputtered $\mathrm{AlN}-\mathrm{ZnO}$ film with an $\mathrm{Al}$ atomic ratio of $40 \%$ still showed insulated behavior.

Table 1. Carrier concentration, mobility, and resistivity of the as-deposited and annealed undoped $\mathrm{ZnO}$ films as well as the cosputtered AlN-ZnO films at a theoretical Al atomic ratio of $20 \%$ and $40 \%$.

\begin{tabular}{|c|c|c|c|c|c|c|}
\hline \multirow{2}{*}{ Film } & \multicolumn{3}{|c|}{ As-Deposited } & \multicolumn{3}{|c|}{ Annealed } \\
\hline & $n\left(\mathrm{~cm}^{-3}\right)$ & $\mu_{n}\left(\mathrm{~cm}^{2} / \mathrm{V} \cdot \mathrm{s}\right)$ & $\rho(\Omega \cdot \mathrm{cm})$ & $n\left(\mathrm{~cm}^{-3}\right)$ & $\mu_{n}\left(\mathrm{~cm}^{2} / \mathrm{V} \cdot \mathrm{s}\right)$ & $\rho(\Omega \cdot \mathrm{cm})$ \\
\hline Undoped $\mathrm{ZnO}$ & N/A & N/A & $>10^{5}$ & $1.68 \times 10^{19}$ & 12.9 & $2.89 \times 10^{-2}$ \\
\hline AlN-ZnO (20\%) & $6.50 \times 10^{18}$ & 1.8 & $5.49 \times 10^{-1}$ & $6.83 \times 10^{19}$ & 9.0 & $1.02 \times 10^{-2}$ \\
\hline AlN-ZnO (40\%) & N/A & N/A & $>10^{5}$ & N/A & N/A & $>10^{5}$ \\
\hline
\end{tabular}

The reason responsible for the annealed undoped $\mathrm{ZnO}$ film possessed a high electron carrier concentration $\left(\sim 1.7 \times 10^{19} \mathrm{~cm}^{-3}\right)$ with a hall mobility, $\mu_{n}$, of $12.9 \mathrm{~cm}^{2} / \mathrm{V} \cdot \mathrm{s}$ was attributed to the presence of the native oxygen vacancies $\left(\mathrm{V}_{\mathrm{O}}\right)$ during the film re-crystallization. In addition, this post-annealing treatment also led to both an increase in carrier concentration $\left(\sim 6.8 \times 10^{19} \mathrm{~cm}^{-3}\right)$ and hall mobility $\left(9.0 \mathrm{~cm}^{2} / \mathrm{V} \cdot \mathrm{s}\right)$ of the $\mathrm{ZnO}$ film cosputtered with $\mathrm{AlN}$ at an $\mathrm{Al}$ atomic ratio of $20 \%$ as compared to that of the as-deposited film, revealing that more $\mathrm{Al}_{\mathrm{Zn}}$ donors had been activated, and the crystalline structure was improved. Moreover, since the donor level of the $\mathrm{Al}_{\mathrm{Zn}}$ was much closer to the conduction band $(\sim 51 \pm 4 \mathrm{meV})$ of the $\mathrm{ZnO}$ compared to that of the $\mathrm{V}_{\mathrm{O}}$ donor $(\sim 566 \pm 62 \mathrm{meV})$, as referred to the report [24], the $\mathrm{Al}_{\mathrm{Zn}}$ donors were prone to be activated at room temperature. Thus, a very high electron concentration was measured from the as-deposited $\mathrm{AlN}-\mathrm{ZnO}$ film at the $\mathrm{Al}$ content of $20 \%$. Figure 3 gives the room temperature PL spectra of the 100-nm thick undoped $\mathrm{ZnO}$ and cosputtered AlN-ZnO films annealed at $700{ }^{\circ} \mathrm{C}$ for $30 \mathrm{~min}$ under vacuum ambient. The signal of the cosputtered AlN-ZnO film with $\mathrm{Al}$ atomic ratios of $20 \%$ and $40 \%$ was magnified by 4 and 20 times, respectively, to make the observations more efficient.

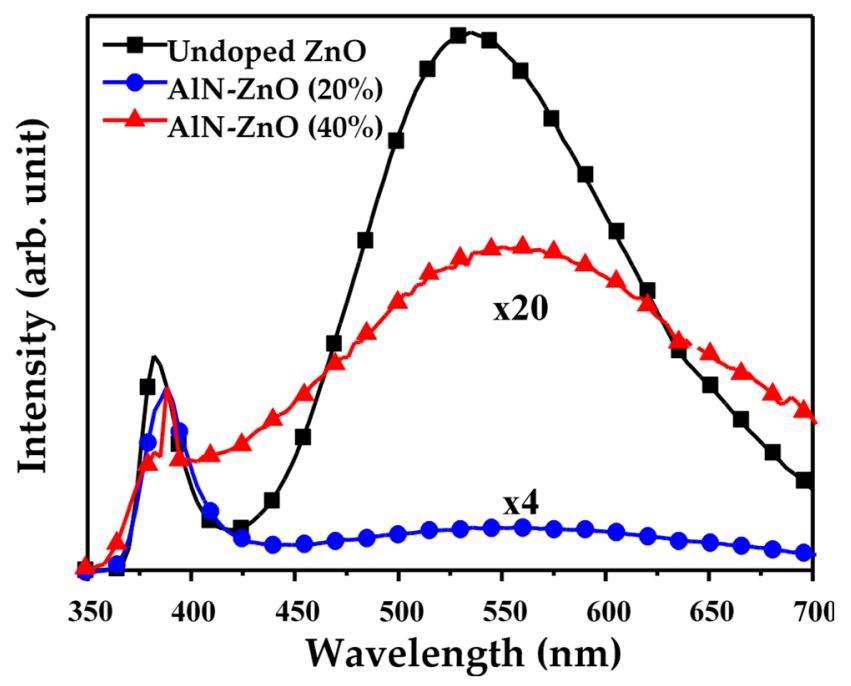

Figure 3. Room temperature PL spectra of the undoped and cosputtered AlN-ZnO films with Al atomic ratios of $20 \%$ and $40 \%$, respectively, annealed at $700{ }^{\circ} \mathrm{C}$ for $30 \mathrm{~min}$ under vacuum ambient.

The PL spectrum of the annealed undoped $\mathrm{ZnO}$ film exhibited a dominant visible wavelength emission and a short-wavelength emission that were in turn assigned as the emissions from the deep-level (DL) and near-band-edge (NBE) transitions, respectively [26,27]. As quoted from the 
reports [28,29], the DL emission at about $535 \mathrm{~nm}$ is mainly composed of the $\mathrm{V}_{\mathrm{O}}$-related transitions as a consequence of the post-annealing treatment under vacuum ambient being favorable for the outdiffusion of the oxygen atoms in the $\mathrm{ZnO}$ film. By contrast, such DL emission was almost absent in the PL spectrum of the AlN-ZnO (20\%) cosputtered film, revealing that the $\mathrm{V}_{\mathrm{O}}$-related transitions were effectively suppressed when AlN was introduced into the $\mathrm{ZnO}$ film. The reason responsible for the marked decrease in the formation of the oxygen vacancies was ascribed to the substitution of $\mathrm{Zn}^{2+}$ lattice sites by the $\mathrm{Al}^{3+}$ ions, which stabilized the oxygen atoms more efficiently due to the bond dissociation energy of Al-O ( 511 kJ/mol) being much higher than that of $\mathrm{Zn}-\mathrm{O}(\sim 211 \mathrm{~kJ} / \mathrm{mol})[15,30]$. In addition, the activation of $\mathrm{Al}$ and $\mathrm{N}$ dopants in the $\mathrm{ZnO}$ film also led to a red shift of the short-wavelength emission from 382 to $388 \mathrm{~nm}$. When the cosputtered $\mathrm{AlN}-\mathrm{ZnO}$ film had an $\mathrm{Al}$ atomic ratio of $40 \%$, the annealed sample emitted a very weak PL signal that featured a short-wavelength peak at $388 \mathrm{~nm}$ and a broad long-wavelength emission extending from near-ultraviolet to near-infrared wavelengths, implying that defects other than $\mathrm{V}_{\mathrm{O}}$ were formed in the $\mathrm{AlN}-\mathrm{ZnO}(40 \%)$ film. Figure 4 shows the XRD patterns of the 300-nm thick undoped $\mathrm{ZnO}$ films and cosputtered $\mathrm{AlN}-\mathrm{ZnO}$ films with $\mathrm{Al}$ atomic ratios of $20 \%$ and $40 \%$, respectively, after annealing at $700{ }^{\circ} \mathrm{C}$ under vacuum ambient for $30 \mathrm{~min}$.

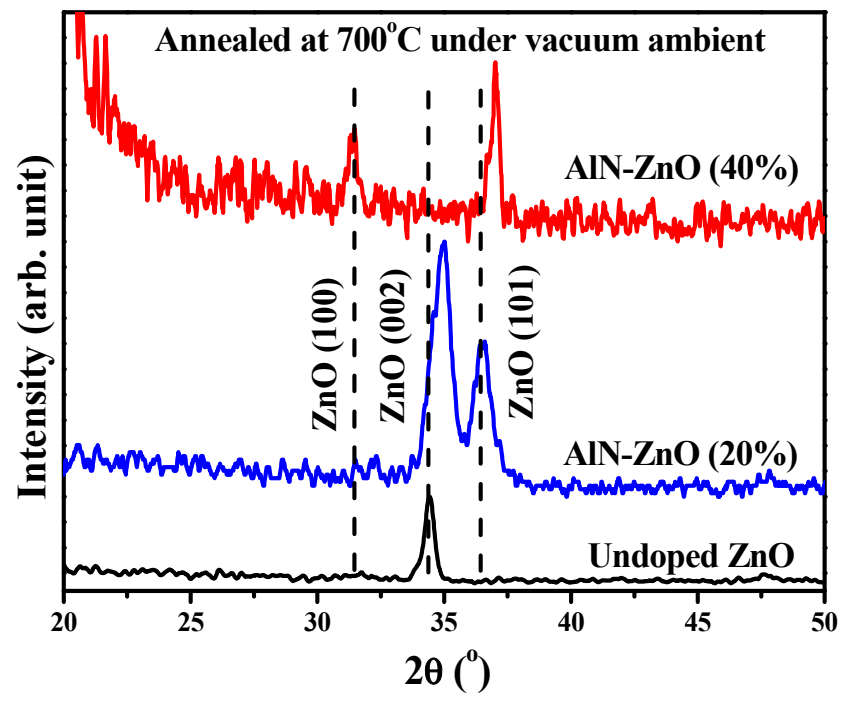

Figure 4. XRD patterns of the undoped $\mathrm{ZnO}$ films and cosputtered $\mathrm{AlN}-\mathrm{ZnO}$ films with $\mathrm{Al}$ atomic ratios of $20 \%$ and $40 \%$, respectively, after annealing at $700{ }^{\circ} \mathrm{C}$ under vacuum ambient for $30 \mathrm{~min}$.

The XRD pattern of the annealed undoped $\mathrm{ZnO}$ film showed only one peak approximately at $34.46^{\circ}$ (assigned as $\mathrm{ZnO}$ (002) phase according to JCPDS no.36-1451), revealing the preferred growth orientation along the $c$-axis. Compared to the undoped $\mathrm{ZnO}$ film, the full width at half maximum (FWHM) of the $\mathrm{ZnO}$ (002) peak was widened and another peak at about $36.62^{\circ}$ (identified as $\mathrm{ZnO}$ (101)) was observed from the XRD pattern of the annealed AlN-ZnO (20\%) film. This implied that the introduction of the AlN into the $\mathrm{ZnO}$ film would break the $c$-axis growth orientation. In addition, the shift of the $\mathrm{ZnO}(002)$ peak to a high $2 \theta$ value $\left(\sim 35.02^{\circ}\right)$ also showed evidence of the activation of $\mathrm{Al}^{3+}$ ions as donor substitutions for $\mathrm{Zn}^{2+}$ lattice sites, since the ionic radius of the $\mathrm{Al}$ atom $(0.053 \mathrm{~nm})$ was smaller than that of the $\mathrm{Zn}$ atom $(0.072 \mathrm{~nm})$. When the theoretical $\mathrm{Al}$ atomic ratio in the AlN-ZnO film further increased to $40 \%$, the structure further degraded to an amorphous-like structure, since the $\mathrm{ZnO}$ (002) phase was hardly observed, and only weak $\mathrm{ZnO}$ (100) and (101) phases were observed in the XRD pattern. Incorporating into the electrical property of these cosputtered AlN-ZnO films, although the activation of the $\mathrm{Al}^{3+}$ donors in the $\mathrm{ZnO}$ matrix was favorable for the enhancement on the electron carriers, the introduced AlN would also break the structure order of the $\mathrm{ZnO}$ film as resulted from the decrease in the $c$-axis growth orientation. Accordingly, the amorphous-like AlN-ZnO film-which implied the undue disorder of the $\mathrm{ZnO}$ structure - exhibited the insulated nature with a very high resistivity $\left(>10^{5} \Omega \Omega \mathrm{cm}\right)$. The surface morphologies of these annealed films observed from the FE-SEM 
measurements are given in Figure 5a-c. In Figure 5a, irregular wedge-like grains were clearly seen on the surface of the annealed undoped $\mathrm{ZnO}$ film.
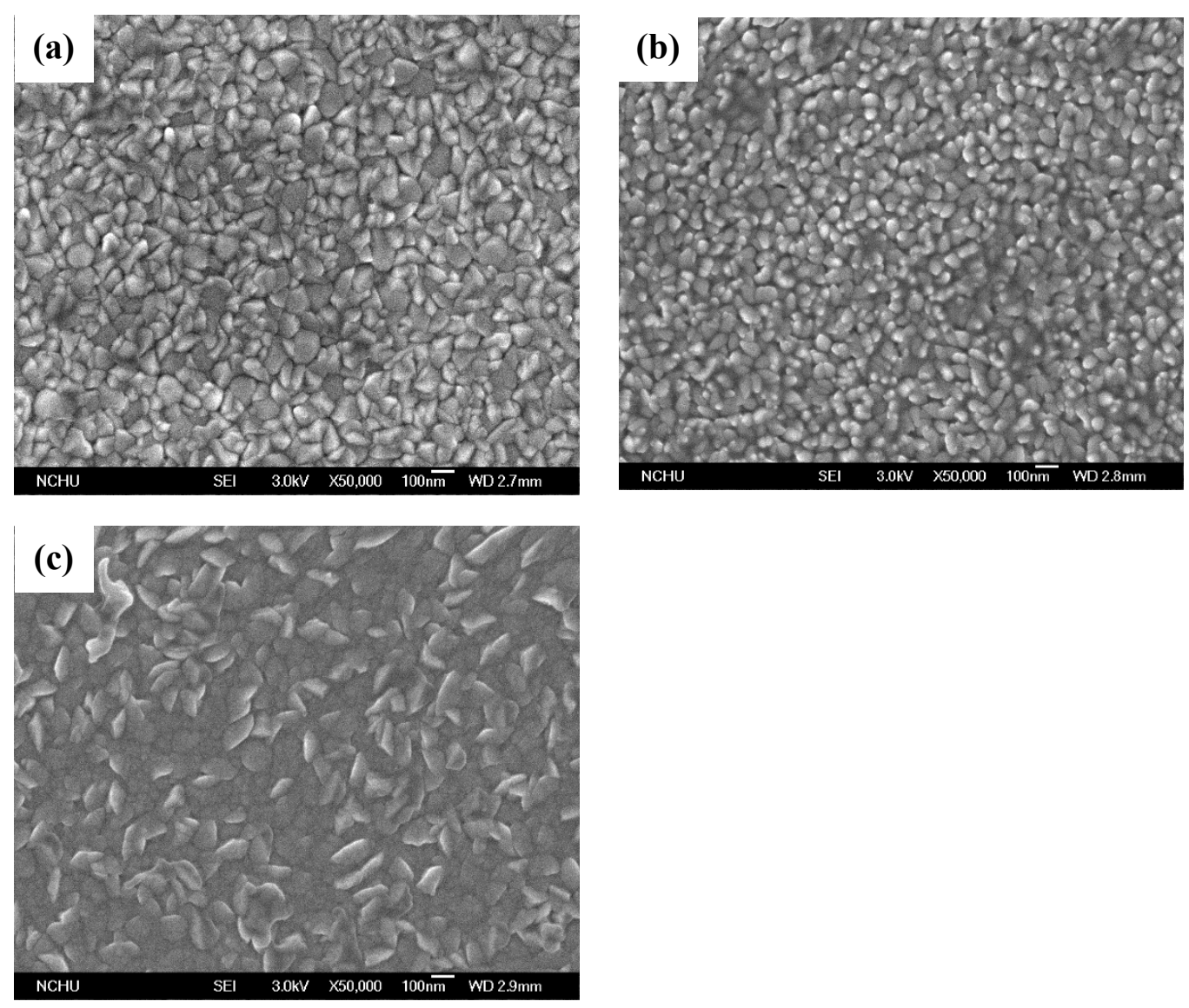

Figure 5. Surface morphologies of the (a) undoped $\mathrm{ZnO}$ films and cosputtered $\mathrm{AlN}-\mathrm{ZnO}$ films with $\mathrm{Al}$ atomic ratios of (b) $20 \%$ and (c) $40 \%$, respectively, after annealing at $700{ }^{\circ} \mathrm{C}$ under vacuum ambient for 30 min from the FE-SEM measurements.

These textured grains distributed over the surface of the AlN-ZnO $(20 \%)$ cosputtered film (Figure $5 b$ ) became small and round-like, which also confirmed an inferior crystalline structure compared to the undoped $\mathrm{ZnO}$ film shown in Figure 4. Furthermore, the amorphous-like structure obtained from the $\mathrm{ZnO}$ film cosputtered with the $\mathrm{AlN}$ at a theoretical $\mathrm{Al}$ atomic ratio of $40 \%$ provided an ambiguous surface morphology with sheet-like protrusions, as observed from Figure 5c.

Based on the investigations of the annealed cosputtered AlN-ZnO films, the introduction of AlN into the $\mathrm{ZnO}$ film resulted in a widening of the optical energy, and was also beneficial for suppressing the formation of native oxygen vacancies. The undoped $\mathrm{ZnO}$ film sandwiched in the cosputtered AlN-ZnO films with high optical energy bandgap was then designed for the purpose of confining the carriers in the undoped $\mathrm{ZnO}$ film. The electrical properties of the undoped $\mathrm{ZnO}$ film deposited onto the substrate with and without an $\mathrm{AlN}-\mathrm{ZnO}(20 \%)$ buffer layer, as well as the $\mathrm{ZnO}$ film sandwiched in the cosputtered AlN-ZnO films, after annealing at $700{ }^{\circ} \mathrm{C}$ under vacuum ambient for $30 \mathrm{~min}$ are summarized in Table 2. The resistivity of the $\mathrm{ZnO}$ film deposited onto an AlN-ZnO buffer layer and the $\mathrm{AlN}-\mathrm{ZnO} / \mathrm{ZnO} / \mathrm{AlN}-\mathrm{ZnO}$ double heterojunction structure were both lower than the $\mathrm{ZnO}$ film directly deposited onto the silicon substrate. The main reason for the improvement in the structure resistance seemed to be different when considering their different impacts on carrier concentration and mobility. For the undoped $\mathrm{ZnO}$ film deposited onto the AlN-ZnO buffer layer, the slight improvement in structure resistivity $\left(\sim 2.68 \times 10^{-2} \Omega \cdot \mathrm{cm}\right)$ as compared to the $\mathrm{ZnO}$ film directly deposited on the substrate $\left(\sim 2.89 \times 10^{-2} \Omega \cdot \mathrm{cm}\right)$ was attributed to an almost double increase in carrier mobility (from 12.9 
to $\left.24.4 \mathrm{~cm}^{2} / \mathrm{V} \cdot \mathrm{s}\right)$, even with a decrease in structure carrier concentration $\left(\sim 9.6 \times 10^{18} \mathrm{~cm}^{-3}\right)$. This implied that the $\mathrm{ZnO}$ film deposited onto the AlN-ZnO buffer layer was beneficial for reducing the mechanisms of the impurity and/or lattice scatterings for carriers transport in the $\mathrm{ZnO}$ film. In contrast, for a cosputtered AlN-ZnO barrier layer coated onto the $\mathrm{AlN}-\mathrm{ZnO} / \mathrm{ZnO}$ structure, there was a marked reduction in structure resistivity of about $7.02 \times 10^{-3} \Omega \cdot \mathrm{cm}$, which was mainly attributed to an obvious increase in the carrier concentration $\left(\sim 4.6 \times 10^{19} \mathrm{~cm}^{-3}\right)$. This revealed that indiffusion of the $\mathrm{Al}^{3+}$ ions as donor substitutions for the $\mathrm{Zn}^{2+}$ lattice sites in the undoped $\mathrm{ZnO}$ film resulted in an increase in the electron carriers, which became the main mechanism responsible for the reduction in the structure resistivity. The crystalline structures investigated from XRD measurements for these annealed samples are shown in Figure 6.

Table 2. Carrier concentration, mobility, and resistivity of the undoped $\mathrm{ZnO}$ film deposited onto the substrate with and without an $\mathrm{AlN}-\mathrm{ZnO}(20 \%)$ buffer layer as well as the $\mathrm{ZnO}$ film sandwiched in the AlN-ZnO cosputtered films, after annealing at $700{ }^{\circ} \mathrm{C}$ under vacuum ambient for $30 \mathrm{~min}$ (the crystal size, $D$, evaluated from the full width at half maximum (FWHM) of the $\mathrm{ZnO}$ (002) phase in the XRD patterns also is given).

\begin{tabular}{ccccc}
\hline Structure & $\boldsymbol{n}\left(\mathbf{c m}^{-3}\right)$ & $\boldsymbol{\mu}_{n}\left(\mathbf{c m}^{2} / \mathbf{V} \cdot \mathbf{s}\right)$ & $\rho(\Omega \cdot \mathbf{c m})$ & $\boldsymbol{D}(\mathbf{n m})$ \\
\hline Undoped ZnO & $1.68 \times 10^{19}$ & 12.9 & $2.89 \times 10^{-2}$ & 22.5 \\
ZnO/AlN-ZnO & $9.56 \times 10^{18}$ & 24.4 & $2.68 \times 10^{-2}$ & 28.7 \\
AlN-ZnO/ZnO/AlN-ZnO & $4.55 \times 10^{19}$ & 19.6 & $7.02 \times 10^{-3}$ & 28.1 \\
\hline
\end{tabular}

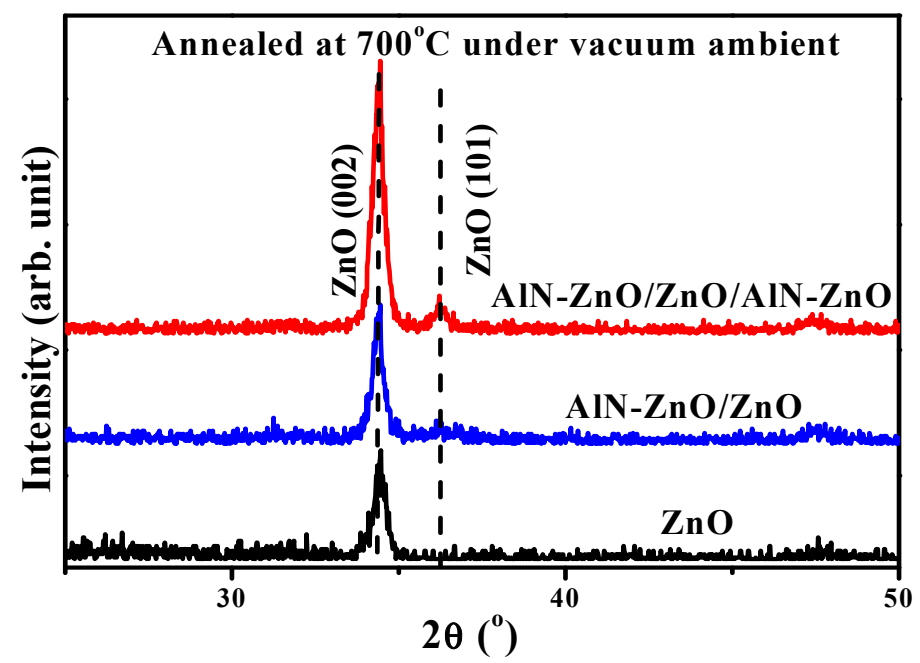

Figure 6. $\mathrm{XRD}$ patterns of the undoped $\mathrm{ZnO}$ film deposited onto the substrate with and without an AlN-ZnO buffer layer, as well as the undoped $\mathrm{ZnO}$ film sandwiched in the cosputtered AlN-ZnO films, after annealing at $700{ }^{\circ} \mathrm{C}$ under vacuum ambient for $30 \mathrm{~min}$.

All of these samples show a preferred c-axis $\mathrm{ZnO}(002)$ growth orientation. Compared with the diffraction pattern of undoped $\mathrm{ZnO}$ film directly deposited onto the substrate, film deposited onto an AlN-ZnO buffer layer resulted in an intense $\mathrm{ZnO}(002)$ signal with a peak position $\left(\sim 34.44^{\circ}\right)$ closer to that which appeared in the bulk $\mathrm{ZnO}$ film $\left(\sim 34.43^{\circ}\right)$, revealing that the internal stress residing in the undoped $\mathrm{ZnO}$ film was further optimized [26]. By adapting the Debye-Scherer formula, crystal size, $D$, is obtainable from of the FWHM of the preferred orientation $(\mathrm{ZnO}(002))$ [31]:

$$
D=\frac{\mathrm{k} \lambda}{\beta \cos \theta}
$$

where $\mathrm{k}$ is a constant; $\lambda$ is the wavelength of the X-ray radiation; and $\beta$ and $\theta$ are the FWHM in radians and the diffraction peak position of the $\mathrm{ZnO}(002)$ phase, respectively. The crystal size of the undoped 
ZnO film deposited onto an AlN-ZnO buffer layer, as listed in Table 2, increased from about 23 to 29 $\mathrm{nm}$. The growth of the crystal size for the undoped $\mathrm{ZnO}$ film deposited onto the AlN-ZnO buffer layer, which corresponded to fewer grain boundaries, was beneficial for lowering the possibility of carrier scattering, and thereby resulted in the apparent increase in carrier mobility shown in Table 2.

When AlN-ZnO was coated onto the $\mathrm{AlN}-\mathrm{ZnO} / \mathrm{ZnO}$ structure, the $\mathrm{ZnO}$ (002) signal was more intense than that in the spectrum of the $\mathrm{AlN}-\mathrm{ZnO} / \mathrm{ZnO}$ structure, while the peak position and FWHM of the $\mathrm{ZnO}(002)$ phase were almost identical to that of the $\mathrm{AlN}-\mathrm{ZnO} / \mathrm{ZnO}$ structure. In addition, another weak diffraction peak associated with the $\mathrm{ZnO}$ (101) phase mainly emerged from the top AlN-ZnO layer, which was also observed in the XRD spectrum. The room temperature PL spectra of the undoped $\mathrm{ZnO}$ film deposited onto the substrate with and without an $\mathrm{AlN}-\mathrm{ZnO}(20 \%)$ buffer layer are shown in Figure 7.

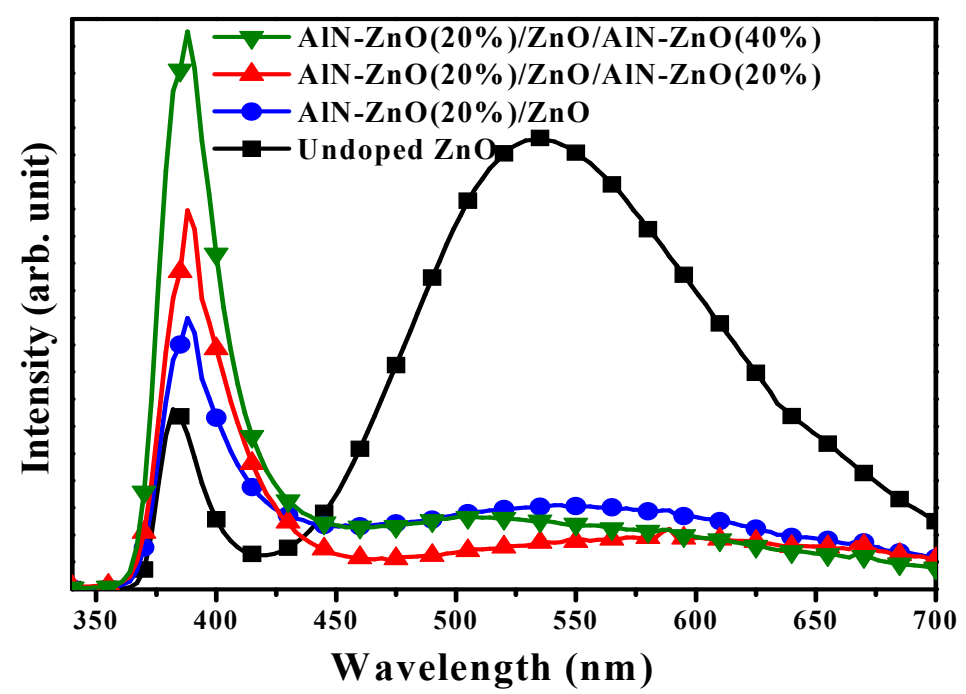

Figure 7. Room temperature photoluminescence (PL) spectra of the undoped $\mathrm{ZnO}$ film deposited onto the substrate with and without an $\mathrm{AlN}-\mathrm{ZnO}$ buffer layer, as well as the $\mathrm{AlN}-\mathrm{ZnO} / \mathrm{ZnO}$ heterojunction structure coated by a cosputtered AlN-ZnO film at the $\mathrm{Al}$ atomic ratios of $20 \%$ and $40 \%$, respectively, after annealing at $700{ }^{\circ} \mathrm{C}$ under vacuum ambient for $30 \mathrm{~min}$.

Compared to the undoped $\mathrm{ZnO}$ film directly deposited onto the substrate, the visible wavelength luminescence associated with the DL transitions in the $\mathrm{ZnO}$ film almost was absent in the PL spectrum of the undoped $\mathrm{ZnO}$ film deposited onto the AlN-ZnO buffer layer, and thereby only one peak was measured around the ultraviolet wavelength. Thus, the native defects in the $\mathrm{ZnO}$ film associated with the oxygen vacancies were effectively suppressed as it was deposited onto the cosputtered AlN-ZnO film. Furthermore, although an intense and single UV emission was achievable from the AlN-ZnO/ZnO structure, this peak red-shifted from 382 toward $388 \mathrm{~nm}$ with a widened FWHM of $30 \mathrm{~nm}$ as compared to the single $\mathrm{ZnO}$ film $(\sim 20 \mathrm{~nm})$. Figure $8 \mathrm{a}$, b give a deconvolution on this $\mathrm{UV}$ light luminescence that emerged from the single $\mathrm{ZnO}$ film and $\mathrm{AlN}-\mathrm{ZnO} / \mathrm{ZnO}$ structure, respectively, to extract the reason for the changes of peak position and the wide FWHM of this short-wavelength emission. As quoted from previous reports [32-34], the short-wavelength luminescence emitted from the undoped $\mathrm{ZnO}$ film directly deposited onto the substrate (Figure 8a) was deconvoluted into two curves with peaks at 382 and $391 \mathrm{~nm}$, which were in turn characterized as the recombination of the free exciton and bound exciton associated with the donor and/or acceptor impurities, respectively. 

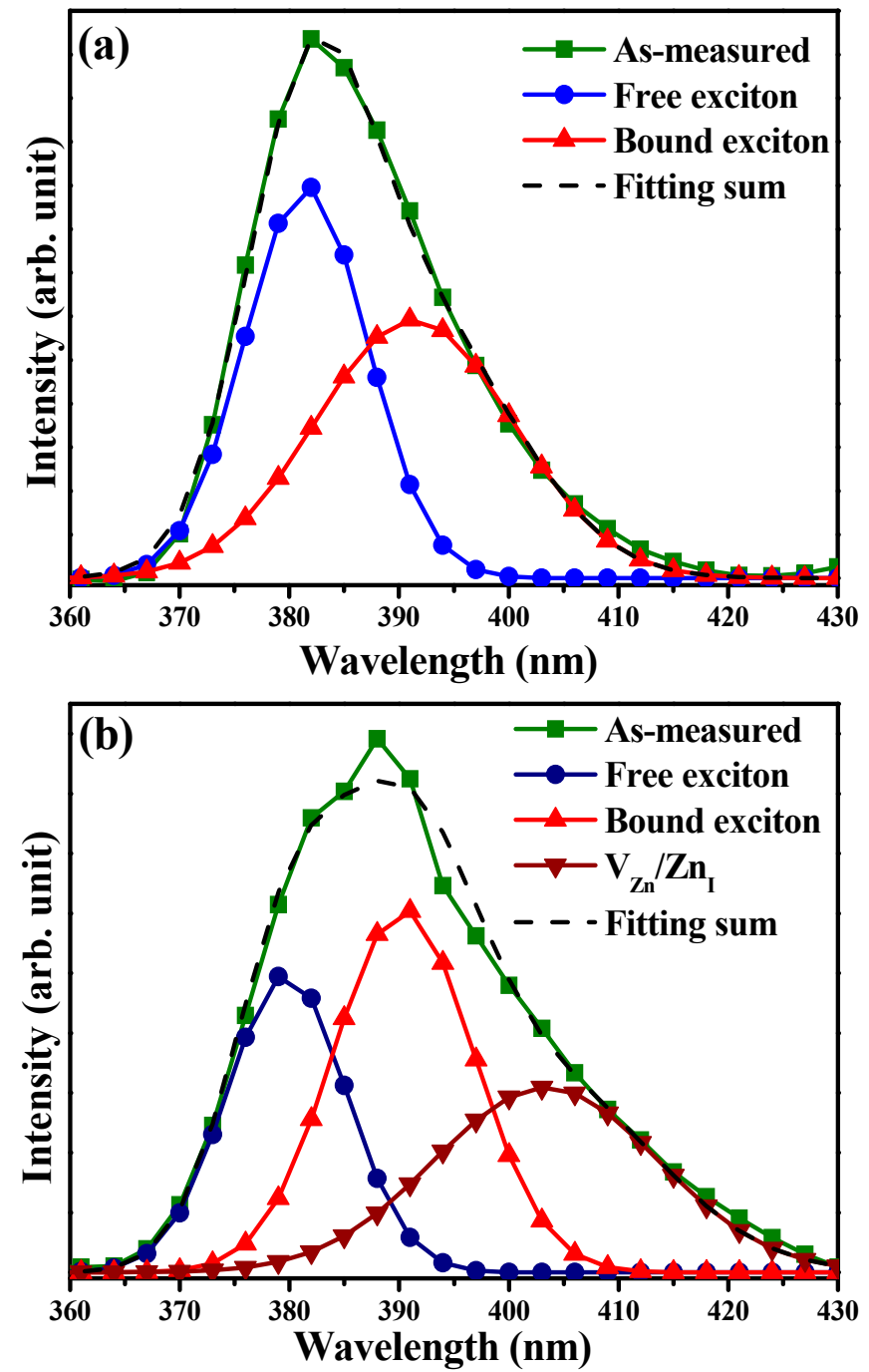

Figure 8. A deconvolution on this UV light luminescence that emerged from the (a) single $\mathrm{ZnO}$ film and (b) AlN-ZnO/ZnO structure, respectively.

In contrast to the single $\mathrm{ZnO}$ film, the relative intensity of the bound exciton emission became higher than that of the free exciton emission as deconvoluted from the short-wavelength luminescence of the $\mathrm{ZnO}$ film deposited onto the cosputtered AlN-ZnO film (Figure 8b), thereby leading to the red-shift of the UV light luminescence. In addition, another weak peak at about $403 \mathrm{~nm}$ deconvoluted in Figure 8b was likely responsible for widening FWHM of the short-wavelength emission. According to the reports $[24,35]$, the transitions of zinc vacancy $\left(\mathrm{V}_{\mathrm{Zn}}\right) / \mathrm{zinc}$ interstitial $\left(\mathrm{Zn}_{\mathrm{I}}\right)$ in the $\mathrm{ZnO}$ film was responsible for this radiative emission. Although the above-mentioned studies showed that single UV photoluminescence was achievable from the $\mathrm{AlN}-\mathrm{ZnO} / \mathrm{ZnO}$ heterojunction structure due to the suppression of native defects related to oxygen vacancies in the undoped $\mathrm{ZnO}$ film, luminescence intensity was limited due to defects distributed over the $\mathrm{ZnO}$ surface and the low recombination efficiency of the photogenerated electron-hole pairs (ehps) in the active $\mathrm{ZnO}$ film. With the aims to passivate the surface states of the $\mathrm{ZnO}$ film and also restrict the radiative recombination of the photogenerated ehps within the $\mathrm{ZnO}$ active layer, a cosputtered AlN-ZnO film with a wider optical energy bandgap was designed to consecutively deposit onto the undoped $\mathrm{ZnO}$ film. The PL spectra of the $\mathrm{AlN}-\mathrm{ZnO} / \mathrm{ZnO}$ heterojunction structure coated by a cosputtered $\mathrm{AlN}-\mathrm{ZnO}$ film at the $\mathrm{Al}$ atomic ratios of $20 \%$ and $40 \%$, respectively are given in Figure 7 . The enhancement of the UV light luminescence for the $\mathrm{AlN}-\mathrm{ZnO} / \mathrm{ZnO}$ structure coated by the cosputtered AlN-ZnO film at an atomic ratio of $20 \%$ as a result of the improved confinement of the photogenerated ehps in the $\mathrm{ZnO}$ active layer was 
significant. The structure coated by the cosputtered AlN-ZnO film at an atomic ratio of $40 \%$ had a wide optical energy bandgap of $3.58 \mathrm{eV}$, and the resulting UV light luminescence could be further optimized to a factor that was about two times higher than that of the luminescence from the $\mathrm{AlN}-\mathrm{ZnO} / \mathrm{ZnO}$ heterojunction structure. Figure 9 a shows the elemental depth profiles of the $\mathrm{Al}, \mathrm{N}, \mathrm{Zn}$, and $\mathrm{O}$ atoms for the AlN-ZnO (20\%)/ZnO/AlN-ZnO (40\%) double heterojunction structure from AES measurement (the inset figure (Figure 9b) shows the symmetric AlN-ZnO (40\%)/ZnO/AlN-ZnO (40\%) DH structure with the thickness of about $35 \mathrm{~nm} / 50 \mathrm{~nm} / 35 \mathrm{~nm}$ conducted from the cross-sectional TEM observations).

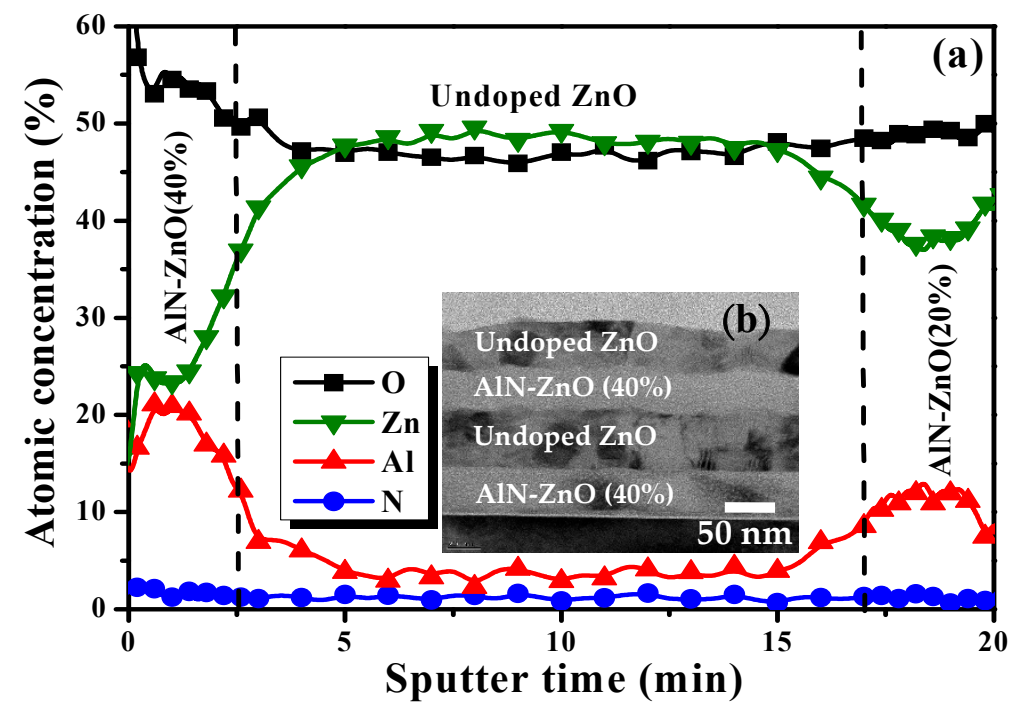

Figure 9. (a) Elemental depth profiles of the $\mathrm{AlN}-\mathrm{ZnO}(20 \%) / \mathrm{ZnO} / \mathrm{AlN}-\mathrm{ZnO}(40 \%)$ double heterojunction structure from Auger electron spectroscopy (AES) measurement ((b) symmetric AlN-ZnO $(40 \%) / \mathrm{ZnO} / \mathrm{AlN}-\mathrm{ZnO}(40 \%) \mathrm{DH}$ structure conducted from the cross-sectional TEM observations).

Layers of the cosputtered $\mathrm{AlN}-\mathrm{ZnO}$ and undoped $\mathrm{ZnO}$ films can be identified through the evolution of these elements. At the bulk of the undoped $\mathrm{ZnO}$ region, the elemental concentration of the $\mathrm{O}$ atoms was a little lower than that of the $\mathrm{Zn}$ atoms, whereas the atomic concentration of the $\mathrm{O}$ element was gradually increased around the $\mathrm{AlN}-\mathrm{ZnO} / \mathrm{ZnO}$ interface. At the cosputtered $\mathrm{AlN}-\mathrm{ZnO}$ region, the $\mathrm{Al}$ element distributed over the top layer almost was higher by double over that of the $\mathrm{Al}$ atoms at the underlayer, while the atomic concentration of the $\mathrm{N}$ element at the cosputtered AlN-ZnO films was limited to a low value of about 1.5 at.\% to 2 at. $\%$, revealing the insolubility of nitrogen atoms into the cosputtered AlN-ZnO film, as described previously [23]. In addition, the indiffusion of $\mathrm{Al}$ atoms into the undoped $\mathrm{ZnO}$ film was evident, as an extending tail was observed around the $\mathrm{AlN}-\mathrm{ZnO} / \mathrm{ZnO}$ interface. The indiffusion of the $\mathrm{Al}$ atoms resulted in an increase of $\mathrm{O}$ atoms at the $\mathrm{AlN}-\mathrm{ZnO} / \mathrm{ZnO}$ interface further confirmed the mechanism responsible for the improvement in the structure resistivity owing to the activation of the $\mathrm{Al}_{\mathrm{Zn}}$ donors and suppression of the $\mathrm{V}_{\mathrm{O}}$ defects in the undoped $\mathrm{ZnO}$ film.

\section{Conclusions}

In conclusion, the crystalline structure and PL emission of a sputter-deposited undoped $\mathrm{ZnO}$ film annealed at $700{ }^{\circ} \mathrm{C}$ under vacuum ambient for $30 \mathrm{~min}$ was improved due to sandwiching in between two cosputtered AlN-ZnO films. The undoped $\mathrm{ZnO}$ film deposited onto the homogenous cosputtered AlN-ZnO film at a theoretical atomic ratio of $20 \%$ resulted in the crystal growth from 23 to $29 \mathrm{~nm}$ and also enhancement of the $c$-axis preferred growth orientation originating from the release of residual internal stress. The apparent increase in the hall mobility of the $\mathrm{AlN}-\mathrm{ZnO} / \mathrm{ZnO}$ structure provided an evidence of the improvement in the crystallinity of the undoped $\mathrm{ZnO}$ film. In addition, the DL emission at about $535 \mathrm{~nm}$ associated with $\mathrm{V}_{\mathrm{O}}$ transition in the undoped $\mathrm{ZnO}$ film was almost absent, as it was deposited onto the cosputtered AlN-ZnO film. The remarkable reduction in DL emission was 
ascribed to the diffusion of $\mathrm{Al}$ atoms at the $\mathrm{AlN}-\mathrm{ZnO} / \mathrm{ZnO}$ interface being favorable for suppression of the formation of native $\mathrm{V}_{\mathrm{O}}$ defects in the undoped $\mathrm{ZnO}$ film. The activation of the $\mathrm{Al}_{\mathrm{Zn}}-\mathrm{O}$ donors originating from indiffusion of the $\mathrm{Al}$ atoms in the undoped $\mathrm{ZnO}$ film also resulted in a red-shift of the UV emission from 382 to $388 \mathrm{~nm}$ with a wide FWHM. The intensity of the UV emission was enhanced along with a cosputtered $\mathrm{AlN}-\mathrm{ZnO}(20 \%)$ barrier layer deposited onto the AlN-ZnO/ZnO heterojunction structure due to the increase in the photogenerated ehps recombination. The efficiency of the photogenerated ehps recombination was further optimized by altering the cosputtered AlN-ZnO barrier layer at an atomic ratio of $40 \%$. This $\mathrm{AlN}-\mathrm{ZnO} / \mathrm{ZnO} / \mathrm{AlN}-\mathrm{ZnO}$ double heterojunction structure, which emitted a single and intense UV light as a consequence of the fewer native $V_{O}$ defects and quality carrier confinement within the active $\mathrm{ZnO}$ film, is a characteristic well-suited for developing ZnO-based optoelectronic devices at a short-wavelength application.

Author Contributions: Conceptualzation, D.S.L.; Methodology, Y.K.Z. and Y.Z.Z.; Software and validation, R.H.H.; Investigation and formal analysis, H.Y.L. and C.T.L.; Resources, R.H.H.; Data curation, H.Y.L. and C.T.L.; Writing-original draft preparation, D.S.L.; Writing-review and editing, H.Y.L. and C.T.L.; Visualization, D.S.L.; All authors read and approved the final version of the manuscript to be submitted.

Funding: This research was funded by Ministry of Science and Technology under MOST 103-2221-E-150 -067 and funded by ITRI and MIRDC.

Conflicts of Interest: The authors declare that there is no conflict of interests regarding the publication of this paper.

\section{References}

1. Lu, Y.-J.; Li, H.-F.; Shan, C.-X.; Li, B.-H.; Shen, D.-Z.; Zhang, L.-G.; Yu, S.-F. Improved performance of ZnO light-emitting devices by introducing a hole-injection layer. Opt. Express 2014, 22, 17524-17531. [CrossRef] [PubMed]

2. Ibupoto, Z.H.; Khun, K.; Eriksson, M.; AlSalhi, M.; Atif, M.; Ansari, A.; Willander, M. Hydrothermal growth of vertically aligned $\mathrm{ZnO}$ nanorods using a biocomposite seed layer of $\mathrm{ZnO}$ nanoparticles. Materials 2015, 6, 3584-3597. [CrossRef] [PubMed]

3. Tsai, B.-S.; Chiu, H.-J.; Chen, T.-H.; Lai, L.-W.; Ho, C.-C.; Liu, D.-S. Dual-wavelength electroluminescence from an $n-\mathrm{ZnO} / p-\mathrm{GaN}$ heterojunction light emitting diode. Appl. Surf. Sci. 2015, 354, 74-78. [CrossRef]

4. Fujiwara, H.; Suzuki, T.; Niyuki, R.; Sasaki, K. Observation of non-classical correlations in sequential measurements of photon polarization. New J. Phys. 2016, 18, 103046. [CrossRef]

5. Lehraki, N.; Aida, M.; Abed, S.; Attaf, N.; Attaf, A.; Poulain, M. ZnO thin films deposition by spray pyrolysis: Influence of precursor solution properties. Curr. Appl. Phys. 2012, 12, 1283-1287. [CrossRef]

6. Chiu, H.J.; Chen, T.H.; Lai, L.W.; Lee, C.T.; Hong, J.D.; Liu, D.S. The achievement of a zinc oxide-based homo-junction diode using radio frequency magnetron cosputtering system. J. Nanomater. 2015, 2015, 284835.

7. Edalati, K.; Shakiba, A.; Vahdati-Khaki, J.; Zebarjad, S.M. Low-temperature hydrothermal synthesis of ZnO nanorods: Effects of zinc salt concentration, various solvents and alkaline mineralizers. Mater. Res. Bull. 2016, 74, 374-379. [CrossRef]

8. Shkurmanov, A.; Sturm, C.; Franke, H.; Lenzner, J.; Grundmann, M. Low-temperature PLD-growth of ultrathin $\mathrm{ZnO}$ nanowires by using $\mathrm{Zn}_{x} \mathrm{Al}_{1-x} \mathrm{O}$ and $\mathrm{Zn}_{x} \mathrm{Ga}_{1-x} \mathrm{O}$ seed layers. Nanoscale Res. Lett. 2017, $12,134$. [CrossRef]

9. Zhang, Y.; Zheng, H.; Su, J.; Lin, B.; Fu, Z. Effects of sic buffer layer on the optical properties of ZnO films grown on $\mathrm{Si}$ (111) substrates. J. Lumin. 2007, 124, 252-256. [CrossRef]

10. Xu, L.; Shi, L.; Li, X. Effect of $\mathrm{TiO}_{2}$ buffer layer on the structural and optical properties of $\mathrm{ZnO}$ thin films deposited by E-beam evaporation and sol-gel method. Appl. Surf. Sci. 2008, 255, 3230-3234. [CrossRef]

11. Guo, W.; Allenic, A.; Chen, Y.B.; Pan, X.Q.; Tian, W.; Adamo, C.; Schlom, D.G. ZnO epitaxy on (111) Si using epitaxial $\mathrm{Lu}_{2} \mathrm{O}_{3}$ buffer layers. Appl. Phys. Letts. 2008, 92, 072101. [CrossRef]

12. Park, J.; Hong, S.; Minegishi, T.; Im, I.; Park, S.; Hanada, T.; Chang, J.; Cho, M.; Yao, T. The high quality $\mathrm{ZnO}$ growth on $c-\mathrm{Al}_{2} \mathrm{O}_{3}$ substrate with $\mathrm{Cr}_{2} \mathrm{O}_{3}$ buffer layer using plasma-assisted molecular beam epitaxy. Appl. Surf. Sci. 2008, 254, 7786-7789. [CrossRef] 
13. Vinodkumar, R.; Lethy, K.; Beena, D.; Detty, A.; Navas, I.; Nayar, U.; Pillai, V.M.; Ganesan, V.; Reddy, V. Effect of ITO buffer layers on the structural, optical and electrical properties of $\mathrm{ZnO}$ multilayer thin films prepared by pulsed laser deposition technique. Sol. Energy Mater. Sol. Cells 2010, 94, 68-74. [CrossRef]

14. Zhang, X.; Ma, S.; Yang, F.; Zhao, Q.; Li, F.; Liu, J. The evolution behavior of microstructures and optical properties of ZnO films using a Ti buffer layer. Ceram. Int. 2013, 39, 7993-7999. [CrossRef]

15. Gan, X.-W.; Wang, T.; Wu, H.; Liu, C. ZnO deposited on $\mathrm{Si}$ (111) with $\mathrm{Al}_{2} \mathrm{O}_{3}$ buffer layer by atomic layer deposition. Vacuum 2014, 107, 120-123. [CrossRef]

16. Wang, W.; Chen, C.; Zhang, G.; Wang, T.; Wu, H.; Liu, Y.; Liu, C. The function of a 60-nm-thick AlN buffer layer in $n-\mathrm{ZnO} / \mathrm{AlN} / p-\mathrm{Si}(111)$. Nanoscale Res. Lett. 2015, 10, 91. [CrossRef] [PubMed]

17. Ohashi, T.; Yamamoto, K.; Nakamura, A.; Temmyo, J. Red Emission from ZnO-Based Double Heterojunction Diode. Jpn. J. Appl. Phys. 2008, 47, 2961-2964. [CrossRef]

18. Li, L.; Yang, Z.; Kong, J.Y.; Liu, J.L. Blue electroluminescence from ZnO based heterojunction diodes with CdZnO active layers. Appl. Phys. Lett. 2009, 95, 232117. [CrossRef]

19. Kong, J.; Liu, J.; Li, L.; Yang, Z. Ultraviolet light emissions in MgZnO/ZnO double heterojunction diodes by molecular beam epitaxy. J. Vac. Sci. Technol. B 2010, 28, C3D10. [CrossRef]

20. Li, Y.; Yao, B.; Deng, R.; Li, B.; Zhang, Z.; Shan, C.; Zhao, D.; Shen, D. A comparative study on electroluminescence from $\mathrm{ZnO}$-based double heterojunction light emitting diodes grown on different lattice mismatch substrates. J. Alloy. Compd. 2013, 575, 233-238. [CrossRef]

21. Shi, Z.-F.; Zhang, Y.-T.; Xia, X.-C.; Zhao, W.; Wang, H.; Zhao, L.; Dong, X.; Zhang, B.-L.; Du, G.-T. Electrically driven ultraviolet random lasing from an $n-\mathrm{MgZnO} / \mathrm{i}-\mathrm{ZnO} / \mathrm{SiO}_{2} / p-\mathrm{Si}$ asymmetric double heterojunction. Nanoscale 2013, 5, 5080-5085. [CrossRef] [PubMed]

22. Pandey, S.K.; Awasthi, V.; Verma, S.; Mukherjee, S. Blue electroluminescence from Sb-ZnO/Cd-ZnO/Ga-ZnO heterojunction diode fabricated by dual ion beam sputtering. Opt. Express 2014, 22, 30983-30991. [CrossRef] [PubMed]

23. Liu, D.S.; Sheu, C.S.; Lee, C.T. Aluminum-nitride codoped zinc oxide films prepared by radio-frequency magnetron cosputtering system. J. Appl. Phys. 2007, 102, 033516. [CrossRef]

24. Yao, S.L.; Hong, J.D.; Lee, C.T.; Ho, C.Y.; Liu, D.S. Determination of activation behavior in the annealed Al-N codoped ZnO films. J. Appl. Phys. 2011, 109, 103504. [CrossRef]

25. Lin, S.-S.; Huang, J.-L.; Lii, D.-F. The effects of r.f. power and substrate temperature on the properties of ZnO films. Surf. Coat. Technol. 2004, 176, 173-181. [CrossRef]

26. Donthu, S.K.; Pan, Z.; Shekhawat, G.S.; Dravid, V.P.; Balakrisnan, B.; Tripathy, S. Near-field scanning optical microscopy of ZnO nanopatterns fabricated by micromolding in capillaries. J. Appl. Phys. 2005, 98, 24304. [CrossRef]

27. Liu, D.S.; Wu, C.Y.; Sheu, C.S.; Tsai, F.C.; Li, C.H. The preparation of piezoelectric ZnO films by RF magnetron sputtering system for layered SAW device applications. Jpn. J. Appl. Phys. 2006, 45, 3531-3536. [CrossRef]

28. Fang, Z.-Q.; Claflin, B.; Look, D.C.; Dong, Y.F.; Mosbacker, H.L.; Brillson, L.J. Surface traps in vapor-phase-grown bulk $\mathrm{ZnO}$ studied by deep level transient spectroscopy. J. Appl. Phys. 2008, 104, 63707. [CrossRef]

29. Ho, C.-C.; Lai, L.-W.; Lee, C.-T.; Yang, K.-C.; Lai, B.-T.; Liu, D.-S. Transparent cosputtered ITO-ZnO electrode ohmic contact to $n$-type $\mathrm{ZnO}$ for $\mathrm{ZnO} / \mathrm{GaN}$ heterojunction light-emitting diode. J. Phys. D Appl. Phys. 2013, 46, 315102. [CrossRef]

30. Gu, Y.-Z.; Lu, H.-L.; Zhang, Y.; Wang, P.-F.; Ding, S.-J. Effects of ZnO seed layer annealing temperature on the properties of $n-\mathrm{ZnO} \mathrm{NWs} / \mathrm{Al}_{2} \mathrm{O}_{3} / p$-Si heterojunction. Opt. Express 2015, 23, 24456-24463. [CrossRef]

31. Liu, D.S.; Tsai, F.C.; Lee, C.T.; Sheu, C.W. Properties of Zinc oxide films cosputtered with various aluminum content at room temperature. Jpn. J. Appl. Phys. 2008, 47, 3056-3062. [CrossRef]

32. Zhao, J.; Hu, L.; Wang, Z.; Chen, J.; Zhao, J.; Fan, Z.; Wu, G. Growth and photoluminescence of ZnO thin films on Si (111) by PLD in oxygen adequate ambient. Vacuum 2007, 81, 1035-1039. [CrossRef]

33. Wang, D.; Zhang, J.; Peng, Y.; Bi, Z.; Bian, X.; Zhang, X.; Hou, X. Plasma-activated nitrogen-doped $p$-type $\mathrm{ZnO}$ thin films with multi-buffer-layers grown on sapphire (0001) by L-MBE. J. Alloys Compd. 2009, 478, 325-329. [CrossRef] 
34. Khan, F.; Baek, S.-H.; Ahmad, N.; Lee, G.H.; Seo, T.H.; Suh, E.-K.; Kim, J.H. Correlation between reflectance and photoluminescent properties of al-rich $\mathrm{ZnO}$ nano-structures. Met. Mater. Int. 2015, 21, 561-568. [CrossRef]

35. Thandavan, T.M.K.; Gani, S.M.A.; Wong, C.S.; Nor, R.M. Enhanced photoluminescence and raman properties of Al-doped $\mathrm{ZnO}$ nanostructures prepared using thermal chemical vapor deposition of methanol assisted with heated brass. PLOS ONE 2015, 10, e0121756. [CrossRef] [PubMed] 